\title{
REFLEXÕES SÔBRE O SÉTIMO COHGRESSO MUNDIAL DE SOCIOLOGIA
}

\author{
Heinrich Rattner*
}

Se fôr verdadeira a afirmação de que sòmente após um congresso bem sucedido começam as reflexõ€s e nascem as novas orientações para estudos e pesquisas, o VII Congresso Mundial de Sociologia difìcilmente poderá ser considerado um certame proveitoso, do ponto de vista do progresso da ciência. Realizado no belíssimo cenário natural de Varna, Bulgária, às margens do Mar Negro, entre 14 e 19 de setembro de 1970, o VII Congresso Mundial de Sociologia reuniu mais de 3.300 sociólogos, vindos de mais de 90 países, que apresentaram quase 1.000 trabalhos científicos para serem discutidos nas diferentes comissões $\mathrm{e} \in \mathrm{m}$ sessães plenárias.

Convocado sob a égide da UNESCO e sob o patrocínio do Presidente do Conselho de Ministros da República Popular da Bulgária, Todor Zhivkov, o Congresso não deixou dúvidas quanto à pretensão da sociologia socialista, em colocar-se, firmemente, como concorrente da tradicional sociologia ocidental.

O fato de um país socialista ter sido escolhido como sede do Congresso; o comparecimento maciço de delegações dêsse bloco - a Bulgária apresentou-se com mais de 500 delegados, tendo o presidente de seu Instituto de Sociologia afirmado haver 800 sociólogos no país, ou seja, 1/10.000 habitantes - e, so-

\footnotetext{
* Professor-adjunto do Departamento de Ciências Socials da

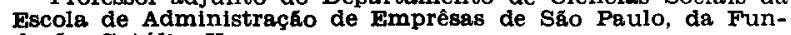
daçio Getúlio Vargas.
}

R. Adm. Emp., Rio de Janeiro bretudo, a própria temática do Congresso, centrada sôbre Sociedades Contemporâneas e Futuras: Prognósticos e Planificação proporcionaram aos seus organizadores o ensejo e oportunidades excelentes de proclamar e divulgar amplamente, perante um vasto auditório internacional, e com ampla cobertura da imprensa falada e escrita (aliás, bastante perturbadora dos próprios trabalhos do Congresso), as vantagens inegáveis de uma ciência social, rigorosamente orientada pelos princípios do marxismo-leninismo.

Notou-se, também, um tremendo esfôrço organizacional, embora frequientemente prejudicado pela inevitável e onipresente burocracia, seguido de uma campanha de divulgação fora do comum, visando a difundir, em todos os países do bloco oriental, a importância e o alcance daquele Congresso.

Assim estruturado, o Congresso parecia representar, para os países socialistas, antes uma questão de prestígio e de afirmação, muito embora as necessidades de prestígio e as qualidades das contribuições científicas não estivessem sempre devidamente relacionadas.

A orientação uniforme dos trabalhos apresentados por sociólogos do bloco oriental, resultou em uma monotonia paralisante de qualquer discussão científica, e transmitiu uma imagem de seus autores menos favorável do que realmente mereciam.

$11(2): 119-123$

Abr./Jun. 1971 
Contràriamente ao que costumava ocorrer nos congressos anteriores, desta vez não houve diálogo nem troca de idéias frutíferas - as sessões se limitaram, geralmente, à apresentação de posições dogmáticas. Assim, o trabalho de Jivko Ochavkov, presidente da Academia Búlgara de Ciências Sociais, sôbre Sociologia e Prognóstico Social; o de Alexei Rumjanzew, vice-presidente da Academia de Ciências da URSS e o de vários outros se assemelharam muito mais a exposições dogmáticas da filosofia marxista-leninista do que a teses elaboradas com finalidade crítica e científica.

Entretanto, apesar da tática partidária comum, houve, por parte de todos os participantes dos países orientais, um interêsse muito agudo e manifesto pelos trabalhos dos sociólogos ocidentais: as cópias de mais ou menos 1.000 contribuições científicas desapareceram de maneira incrìvelmente rápida, o que parece confirmar uma das principais funções dêsse tipo de congresso: servir de local e oportunidade para a troca de relatórios de pesquisa e de estudos para o mundo dos cientistas. Foi decepcionante a posição passiva adotada pelos sociólogos ocidentais, os quais não se empenharam numa crítica científica construtiva das teses dogmáticas de seus colegas do bloco socialista; pior ainda, pode-se afirmar que nem sequer houve confrontação de teses, métodos e teorias, porque, na realidade, não chegou a haver muita comunicação entre os delegados procedentes das duas áreas geopolíticas, o que levou o sociólogo berlinense, $\mathrm{O}$. Flechtheim, a manifestar, por diversas vêzes, críticas mordazes ao Congresso e aos congressistas, acusando a ambos os lados de não passarem de meros representantes de establishments, e censurando os socialistas por suas apresentações uniformes e monótonas.

Realmente, em certos momentos do Congresso, parecia que tanto os sociólogos do Ocidente quanto os do Oriente usavam sua ciência para justificarem, cada um a seu modo, seu respectivo status quo e seu establishment social e político...
O problema da comunicação foi agravado pela divisão lingüística: o Ocidente falava inglês, e o Oriente francês, o que prejudicou ainda mais as reuniões plenárias, que se restringiram a leituras de papers, em salas pràticamente vazias.

As dúvidas quanto à utilidade de congressos mundiais de sociologia levaram um grupo de sociólogos, de composição heterogênea quanto à origem, e radical em suas posições, a elaborar uma proposta, aliás bastante discutida nos bastidores, no sentido de renovar, futuramente, a agenda dos trabalhos, incluindo nela mais trabalhos referentes à problemática política atual, e dando maior ênfase às sociedades do Terceiro Mundo e seus esforços para alcançar maior grau de desenvolvimento.

Seria injusto, todavia, negar certos méritos do Congresso, muito embora não apresentasse resultados brilhantes. De fato, o número de participantes e a organização bastantes rígida, apesar das comissões, grupos de trabalho, mesas-redondas, comissões de pesquisa etc., colocaram sérios obstáculos a uma troca de idéias e de opiniões, da qual poderiam resultar sínteses ou novas hipóteses de trabalho.

Mesmo assim, ficou evidente, ao analisarse alguns tópicos do vasto programa do Congresso, que a sociologia carece, na atualidade, de teorias globais sôbre a mudança social, bem como de conceitos adequados para uma ligação orgânica entre a micro e a macrossociologia. O relatório, ansiosamente aguardado, de Talcott Parsons, sôbre Pesquisa Comparativa e Mudanças Evolucionárias, foi decepcionante, e suas idéias sôbre a sociedade foram taxadas de puramente descritivas e estáticas.

O grupo de trabalho mais freqüentado, nos primeiros dias do Congresso, foi o que tinha como tema central Análise Comparativa de Planejamento em Diferentes Tipos de Sociedade. O trabalho apresentado pela socióloga canadense, Helen Constans, intitulado Elementos Racionais e Irracionais no Planeja- 
mento teve o mérito de enfatizar a oposição que divide Oriente e Ocidente. Questionando a eficiência do planejamento socialista, $H$. Constans afirmou que: a) os planos elaborados nos países socialistas se preocupam, fundamentalmente, com o crescimento econômico e não com o desenvolvimento social; b) falta uma concepção teórica verdadeira ao planejamento socialista e c) nos países socialistas, a ideologia oficial tem provocado efeitos adversos, intervindo nas tarefas práticas do planejamento.

Contra suas teses levantaram-se, em voz uníssona, diversos representantes dos países orientais, que manifestaram sua fé nas idéias e na prática política do partido e sua maneira de gerir a economia e levar a sociedade para um futuro brilhante.

Foram abordados, também, alguns tópicos relativamente novos no campo da pesquisa sociológica, tais como Sociologia da Juventude, num grupo de trabalho intitulado Juventude como Fator de Mudança Social; Sociologia dos Esportes e do Lazer e Sociologia Militar, campo em que, curiosamente, norteamericanos e russos pareciam entender-se muito bem.

A lista dos grupos de trabalho, das comissões de pesquisa, das mesas-redondas, dos grupos $a d$ hoc e das sessões suplementares poderia ser alongada. O que ficou patente, todavia, é que a sociologia se apresenta, hoje, ainda, como uma disciplina dividida em inúmeras idéias e teorias, nem sempre coerentes e convergentes: teses biológicas, psicológicas e psicanalíticas; teorias orientadas pela matemática, filosofia ou pelo Positivismo; uma ciência social que ora se apresenta como disciplina compreensiva, ora como método cibernético ou dialético, oferecendo, alternadamente, interpretações materialistas, idealistas ou fenomenológicas.

Entretanto, como bem frisou P. Sorokin, no Congresso Internacional de 1966, apesar de tôdas essas tendências divergentes, existe um núcleo comum de conhecimentos e de metodologia que leva essas correntes à con- vergência, para, finalmente, desembocar numa era de grandes sínteses sociológicas.

E inegável que, num primeiro momento de oposição às grandes sínteses e sistemas explicativos do século passado, a sociologia se tem dirigido para a coleța de fatos empíricos. Muitas vêzes, porém, foram acumulados fatos e mais fatos, sem saber exatamente o que fazer com êles. Chegou-se assim a um impasse, em que, esquecendo-se dos problemas fundamentais do homem e da sociedade humana, se opuseram, de um lado, as grandes sínteses, reconhecidamente insuficientes para explicar a evolução social, e de outro, justificativas empíricas - mecanicistas do existente, ignorando ou abstraindo qualquer fundamento teórico.

O perigo de tornar-se uma microssociologia, abstrata e burocratizada, empenhada no estudo e na análise de detalhes insignificantes, ao mesmo tempo em que elimina de suas atividades e preocupações os problemas fundamentais; enfim, uma sociologia que deixa de ser crítica construtiva do presente e ignora o sujeito ativo e criador do processo histórico, eis alguns dos dilemas que enfrentam os sociólogos, tanto do mundo oriental quanto do ocidental.

Tentando descrever e caracterizar o homem moderno - por mais polêmica que o conceito de modernização tenha despertado entre os sociólogos - deve-se partir das mudanças ocorridas, nas últimas décadas, nas condições ambientais, sociais e culturais: urbanização, educação universal, comunicação de massa, industrialização e politização com essas transformações no condicionamento da vida social, o próprio homem também sofreu mudanças. Tornou-se mais aberto, admite e aceita evolução e reformas, abandonando experiências tradicionais e acolhendo novas idéias e formas de pensar. Em seu relacionamento com seus pares e com os outros, o homem moderno é mais tolerante e democrata, admite opinióes diferentes e não se submete mais passivamente às ordens e opiniões dos seus superiores, apenas por emanarem dêles - êle as passa pelo crivo da crí- 
tica e da razão, pesa argumentos e tenta decidir racionalmente. $O$ respeito pelos outros, suas opinióes e personalidade, tendem a aproximar os homens e os grupos, permitindo prever a eliminação paulatina do etnocentrismo exagerado e das tensọ̃es e conflitos decorrentes.

O homem contemporâneo é diferente de seus antepassados no que se refere ao seu relacionamento com as dimensões do tempo: êle é muito mais orientado para o presente e o futuro do que para o passado; êle é capaz de programar sua vida, livrando-se da superstição e das crenças paralisantes do passado; enfim, essas características do homem moderno - a razão, sua tolerância, sua abertura para o mundo e sua mobilidade - nos autorizam acreditar na possibilidade e viabilidade de determinar e controlar conscientemente os destinos da humanidade.

Todavia, a observação da realidade, da prática da vida política contemporânea, no Ocidente tanto quanto no Oriente, nos suscitam dúvidas justificadas quanto às perspectivas acima assinaladas. Nos países altamente industrializados e burocratizados, o sistema sociopolítico parece de tal forma ancorado ideológica e pràticamente nas consciências dos indivíduos, que tôda e qualquer proposta de reforma ou ação no sentido de mudança se tornem utópicos. A dominação da praxis social sôbre a consciência é tão forte, a ponto de sufocar críticas e atividades criadora no seu nascedouro. O pensamento, as aspirações, os alvos dos indivíduos estão sendo guiados e orientados em trilhos preestabelecidos, à medida que a vida das pessoas se desenrola crescentemente em organizações altamente burocratizadas e cientificamente administradas. Em conseqüência, o existente passa a ser considerado imutável e o indivíduo deve, se não quiser entrar em conflito com o sistema, acomodar-se e submeter-se.

São essas condições sociopolíticas mais amplas que estão na origem da crise da sociologia e das ciências sociais, na atualidade: o sociólogo, também, não consegue escapar da tendência geral: é, cada vez mais, difícil para êle indicar e exigir soluções ideais, quando todos parecem conformar-se e aceitar o status quo. Transcender o presente, projetar e planejar o futuro, quando disciplina partidária - política e imobilismo social são elevados a virtudes máximas de nossa época, se tornam tarefas que exigem esforços incomuns.

A situação se apresenta diferentemente nos países em desenvolvimento, onde o sistema social ainda não desenvolveu a rigidez característica das tendências totalitárias semelhantes aos países industrializados, ocidentais e orientais. Colocado neste contexto e à luz da praxis social e política, em nossa sociedade contemporânea, seria exigir e esperar em demasia do sociólogo que êle forneça soluções e blue-prints aos conflitos e problemas da sociedade. Essses são universais, no sentido de que alcançam a tôdas as sociedades e agrupamentos que, queiram ou não, são integrados num sistema de trocas mundiais e levados a aplicarem tecnologia e métodos de produção altamente elaborados e sofisticados: industrialização e desenvolvimento; problemas urbanos; juventude em revolta; mudanças na estrutura da família, nas formas e conteúdo do lazer; secularização do pensamento e influência crescente dos meios de comunicação em massa e, last but not least, a aspiração universal à paz e ao bem-estar constituem tão-sòmente alguns aspectos das tendências contraditórias nas sociedades industriais e nas em desenvolvimento. Nestas circunstâncias, o sociólogo poderá - na hipótese de livrar-se das pressões do ambiente e eliminar outros vieses - analisar o presente e suas tendências conflitivas $e$, assim, facilitar a compreensão das condições societárias reais em que vivemos. As conclusões desta análise, sob forma de medidas concretas e conscientes de intervenção dirigida e planejada, pertencem aos estadistas e políticos, aos que detêm o poder de fato e, claramente, não aos estudiosos dos diferentes ramos das ciências sociais .

Parece fora de dúvida que uma análise e projeções dos problemas que afligem quase 
todos os países, atualmente, indicariam como solução ideal a construção de uma sociedade mundial, eliminando barreiras e preconceitos de qualquer espécie. Entretanto, à luz das desigualdades, tensões e conflitos que caracterizam a época contemporânea, a formação de uma sociedade mundial parece bastante problemática e distante. Mesmo as chamadas "sociedades industrializadas", tanto as do Ocidente quanto as do Oriente, não apresentam estruturas suficientemente sólidas para concretizarem uma integração em escala mundial: cada Estado nacional enfrenta tantos problemas, inclusive o da integração, através da criação de um mercado nacional, em que participem como produtores e consumidores, a maioria da população, de vastas áreas em escala regional e nacional, que seria sumamente utópico dêles exigir a concretização de um projeto de integração internacional. Como foi muito bem frisado, ainda no século passado, ... "para que os povos se unam realmente, êles devem desenvolver interêsses e objetivos em comum. Entretanto, para que haja interêsses comuns, será necessário alterar relações que condicionam e perpetuam a espoliação e a denominação de uns povos pelos outros"...

Indubitàvelmente, ocorre um lento e gradual amadurecimento das condições sociais e políticas para a efetivação da unidade e da integração das sociedades nacionais numa só humanidade. $O$ ato político, portanto, seria apenas a forma mais racional dos homens, em sociedade, responderem aos desafios propostos pela sua própria evolução. Se não forem capazes de empregar a razão, a ciência e a tecnologia, enfim, todos os instrumentos maravilhosos criados pelo gênio humano para encontrar uma resposta certa, eficaz e adequada ao desafio, então a ameaça da decadência, do barbarismo e da perpetuação do desafio se tornam inevitáveis.

Porque, no fundo, como dizia B. Russel ... "O homem d€ve esperar aquêle futuro, que êle fôr capaz de criar e construir para si mesmo".

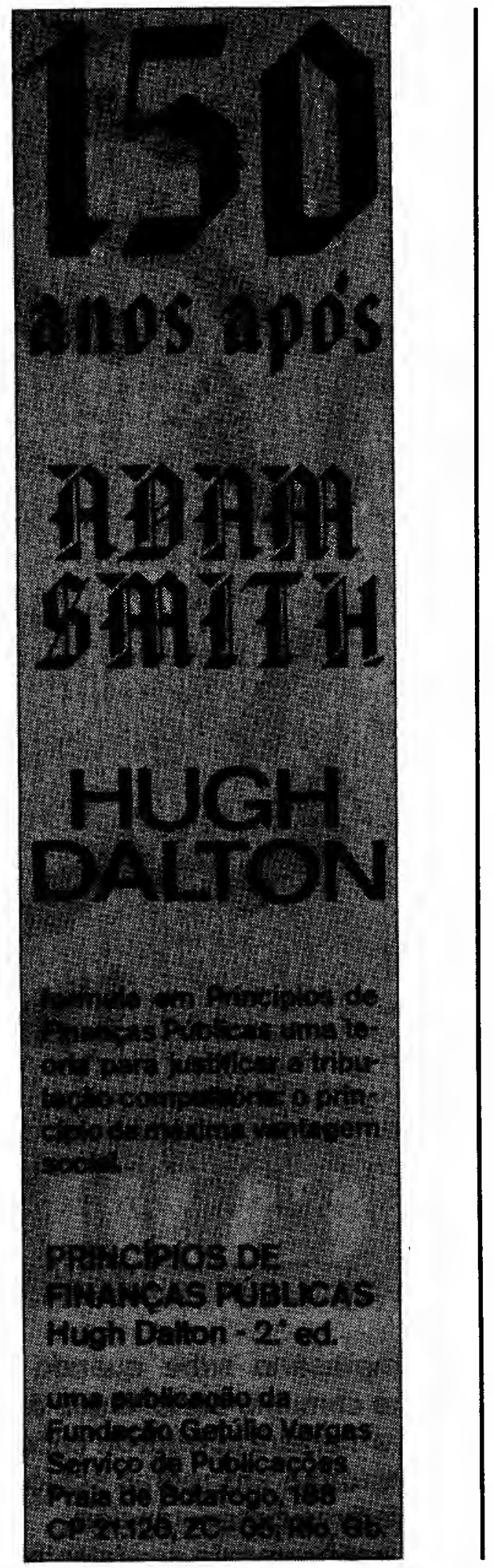

